\title{
CORTICO-PYRAMIDAL INFLUENCES ON THALAMIC SOMATOSENSORY TRANSMISSION IN THE CA T'
}

\author{
Hiroshi Shimazu, ${ }^{2)}$ Nobuo Yanagisawa \\ AND Bill GAROUTTE ${ }^{3)}$ \\ Section of Neurophysiology, Institute of Brain Research, \\ University of Tokyo, Bunkyo-ku, Tokyo, Japan
}

\section{INTRODUCTION}

The functional relations between sensorimotor cortex and ventrobasal thalamus (VB) present important problems which are far from solved, though there have been some investigations of the effects of cortical stimulation on evoked mass responses in the thalamic VB complex ${ }^{16,29)}$. In the present study, the topographical organization of cortical influences on VB neurons has been investigated by recording single unit activity in the VB complex. We have been particularly interested in the possibility that some of the cortical neurons which modulate VB neuronal activity may give rise to fibers in the pyramidal tract.

Functional properties of neurons within the VB complex and their precise locations within the thalamus have been studied extensively by PoGgio and MoUnTCASTLE ${ }^{30)}$. Cortical influences on somatosensory transmission at various levels have also been investigated ${ }^{3,11,12,14,18,26,31}$. In addition, there is some anatomical evidence for corticofugal fibers terminating in the VB complex ${ }^{4,12}$, though it is not known whether these fibers are pyramidal or extrapyramidal.

The present investigations demonstrate certain excitatory and inhibitory relationships between thalamic neurons and topographically related cortical neurons, and also suggest that some of the important cortico-thalamic influences may be mediated via collaterals to fibers running in the pyramidal tract.

Received for publication October 24, 1964

島津 浩; 柳沢信夫,

1) This research was supported by funds from the Ministry of Eduction of Japan.

2) Presently at the Max-Planck-Institut für Hirnforschung, Frankfurt am Main, Niederrad, Germany.

3) Visiting Investigator from the Departments of Anatomy and Neurology, University of California School of Medicine, San Francisco, California. 


\section{METHODS}

These experiments were carried out on 64 adult cats. A tracheal cannula was introduced under ether, then $20 \mathrm{mg} . / \mathrm{kg}$. of pentobarbital (Nembutal, Abbot) was administered intraperitoneally. Ether was discontinued and the following procedures were carried out. Gross stimulating and recording electrodes were applied to the left sensorimotor cortex, a glass microelectrode was inserted into the left VB complex; left pyramidal stimulating electrodes were applied caudally or rostrally to a pyramidal transection in the medullary pyramid; right medial lemniscal stimulating electrodes were inserted through the dorsal column nuclei, and peripheral nerve stimulating electrodes were applied to forepaw and hindpaw nerves. Interactions between stimuli applied through these various electrodes were then studied. A $35 \mathrm{~mm}$. moving film camera was used to photograph the oscilloscope traces.

Only the single minimal dose of pentobarbital was given, and the first records were obtained more than 5 hrs. after the injection, with the animal immobilized with Flaxedil and artificially respirated.

The head of the animal was fixed in a stereotaxic instrument. The dorsal surface of the medulla oblongata was exposed by removing the atlanto-occipital membrane and adjacent occipital bone bilaterally. To reduce brain movement, cerebrospinal fluid was drained through this opening in all experiments.

With the stereotaxic apparatus rotated to bring the animal into the supine position, the medullary pyramid was approached ventrally by removing the basiocciput and dura. On the same (left) side as the later thalamic recording, the pyramid was cut transversely with an iridectomy knife $4 \mathrm{~mm}$. caudally to the border between pons and trapezoid body. Bipolar stimulation electrodes were placed on the surface of the left pyramid $3 \mathrm{~mm}$. rostrally to the transection; i. e. $1 \mathrm{~mm}$. caudally to the ponto-medullary border. These electrodes were prepared (FIG. 1) by cementing two $0.1 \mathrm{~mm}$. silver wires between 2 long acrylite plates $(0.5 \times 4 \times 15 \mathrm{~mm}$.), so that the tips of the wires protruded $0.2 \mathrm{~mm}$. beyond the end of the acrylite plates, with tip separation of $0.5 \mathrm{~mm}$.

FRONTAL VIEW

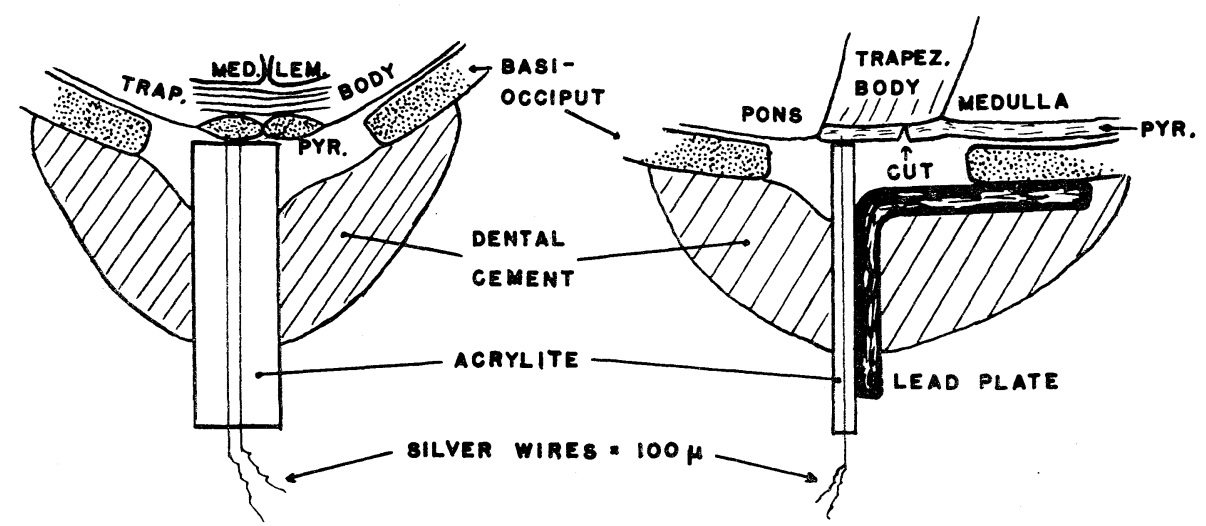

\section{APPLICATION OF PYRAMIDAL ELECTRODES}

FIG. 1. Method of application of stimulating electrodes to the medullary pyramid. The arrow indicates the transection of the pyramid. 
A flexible strip of lead was cemented to the acrylite, and bent so that when its other end was cemented to the basiocciput, the edge of acrylite and the silver wire electrodes were gently apposed to the surface of the pyramid transversely. Then the stereotaxic apparatus and cat were rotated back to the prone position. The electrode placement achieved in this fashion was usually very stable, as judged by the constancy of the cortical response to pyramidal stimulation throughout the experiment.

In 5 cats, these stimulating electrodes were placed $3 \mathrm{~mm}$. caudally, as well as rostrally, to the pyramidal transection.

For medial lemniscal stimulation a pair of steel wires, $0.8 \mathrm{~mm}$. apart and $0.3 \mathrm{~mm}$. in diameter, insulated to their sharpened tips, were inserted $2-3 \mathrm{~mm}$. below the surface of the contralateral (right) dorsal column $2 \mathrm{~mm}$. from the midline at the level of the obex.

The skull and dura were removed over the pericruciate area. Seven or 8 stimulating electrodes were inserted $1.5-2.0 \mathrm{~mm}$. into the postcruciate gyrus, in a transverse line parallel to and $2-3 \mathrm{~mm}$. posterior to the cruciate sulcus. Each electrode was of silver wire $0.1 \mathrm{~mm}$. in diameter, insulated nearly to the tip. Adjacent electrodes were usually $1.5 \mathrm{~mm}$. apart, but sometimes $3.0 \mathrm{~mm}$. Three or 4 stimulating electrodes of the same type were inserted into the precruciate cortex. In acutely or chronically decorticated animals, stimulating electrodes were similarly applied to the exposed white matter in the same relative placement.

For the response evoked in cortex or exposed white matter, a silver ball electrode was placed on the lateral part of the postcruciate gyrus and recorded versus a reference electrode on the cut edge of the scalp. Bipolar recording was also performed, using silver electrodes $0.1 \mathrm{~mm}$. in diameter and $2.0 \mathrm{~mm}$. apart, oriented vertically to the cortical surface.

The following peripheral nerves were stimulated: the superficial radial and dorsal branch of the ulnar (contralaterally or bilaterally), and the contralateral tibial and superficial peroneal. The nerves were cut at the carpal or tarsal joint, laid on bipolar silver stimulating electrodes, and covered with a semi-solid paraffin-vaseline mixture. The cortex was also covered with the same mixture in most experiments.

The only ground was a $3 \times 4 \mathrm{~cm}$. silver plate inserted between the temporalis muscle and skull. All the stimuli were delivered through an isolation transformer, and were rectangular pulses of $0.1 \mathrm{msec}$. duration, either applied singly or in short volleys at 500 per second. The cortex or exposed white matter were stimulated using the inserted silver wire as focal cathode with clips on the cut edge of the scalp as reference anode. Using a d.c. amplifier, the stimulating currents applied to the cortex and to the pyramid were recorded as voltages across a $50 \mathrm{ohm}$ resistor in series with the nervous tissue. The intensity of cortical stimulation was usually 0.8 to $3.0 \mathrm{~mA}$. When the effects of stimulating various cortical areas were under study, stimuli of identical voltages were applied with each cortical electrode. The resistance of each cortical electrode was about $10,000 \mathrm{ohms}$, measured by a $10 \mathrm{~V}$ rectangular pulse of 1 msec. duration.

The stimuli which produced restricted pyramidal excitation (below the threshold of lemniscal excitation) (see DIscussion) were less than $0.6 \mathrm{~mA}$ in intensity. The intensities of stimuli to the medial lemniscus were adjusted to make the cortical evoked potential submaximal or just maximal in amplitude. Usually this occurred at 4. 0-8. $0 \mathrm{~V}$.

The brain directly over the left VB complex was sucked out to a depth of 7-8 mm. after coagulation of the cortical blood vessels with a silver nitrate crystal. The exposed white matter was covered with liquid paraffin, and a glass micropipette was inserted vertically into the medial part of VPL under stereotaxic control, using the 
atlas of JAsper and Ajmone-MArsan ${ }^{199}$. These electrodes were filled with $3 \mathrm{M} . \mathrm{KCl}$, and had resistances of $2-5$ megohms, measured with $200 \mathrm{mV}$ at $50 \mathrm{cps}$. Extracellular unit spikes from VB neurons were led into a two-beam cathode ray oscilloscope through an input cathode follower and a capacity-coupled amplifier with a $50 \mathrm{msec}$. time constant. The oscilloscope trace was recorded on $35 \mathrm{~mm}$. film with a kymograph camera. The cortical potentials were led into the same type of amplifier. Cortical potentials, unit potentials, and stimulation potentials were monitored on a bank of cathode ray oscilloscopes throughout the experiment. The unit activity was also monitored via an audio system.

The left pericruciate cortex, including a part of the coronal and ectosylvian gyri, was removed by suction acutely in 10 cats, and 22-30 days before the experiment in 5 cats.

When cortical conditioning effects on a lemniscally evoked VB unit response were under study, the mean of 10 trials was used for comparisons.

The extent of pyramidal lesions was determined by serial sections of the medulla oblongata stained by the method of KLÜver and BARRERA. When the lesion did not include the entire pyramid, that part of the experiment was discarded. The locations of the microelectrodes were checked by critical inspection of the unit responses to stimulation of the peripheral nerves, medial lemniscus and postcruciate cortex as described under RESULTS.

\section{RESULTS}

\section{Identification of $V B$ neurons.}

The following three were adopted as criteria for identification of a VB neuron in the present experiments; (1) the orthodromic responses to restricted peripheral nerve stimulation, (2) the trans-synaptic responses to medial lemniscal stimulation, and (3) the antidromic responses to postcruciate cortical stimulation.

(1) Peripheral nerve stimulation. Microelectrode penetrations into the ventrobasal nuclear complex of the left thalamus were performed stereotaxically during continuing $1 / \mathrm{sec}$. single-shock stimulation of the contralateral superficial radial or ulnar nerve. The strength of the peripheral nerve stimulus was adjusted to be supramaximal, as judged by the cortical response evoked in the lateral part of the postcruciate gyrus. When negative monophasic or positive-negative diphasic unit potentials were evoked by single-shock stimulation of a peripheral nerve, the unit was further investigated by testing the effects of stimulation of other nerves.

A typical unit response is shown in FIG. 2A. These unit spikes were evoked by stimulation of either contralateral ulnar or superficial radial nerve (FIG. 2Aa and b), but not by shocks to nerves in the hindlimb (FIG. 2Ac and d), or ipsilateral forelimb. This indicates that the neuron has a restricted receptive field, though neither receptive fields nor modalities were examined with natural stimulation in the present experiments. Of the 169 neurons recorded, 96 responded in this way. An additional 34 neurons responded 

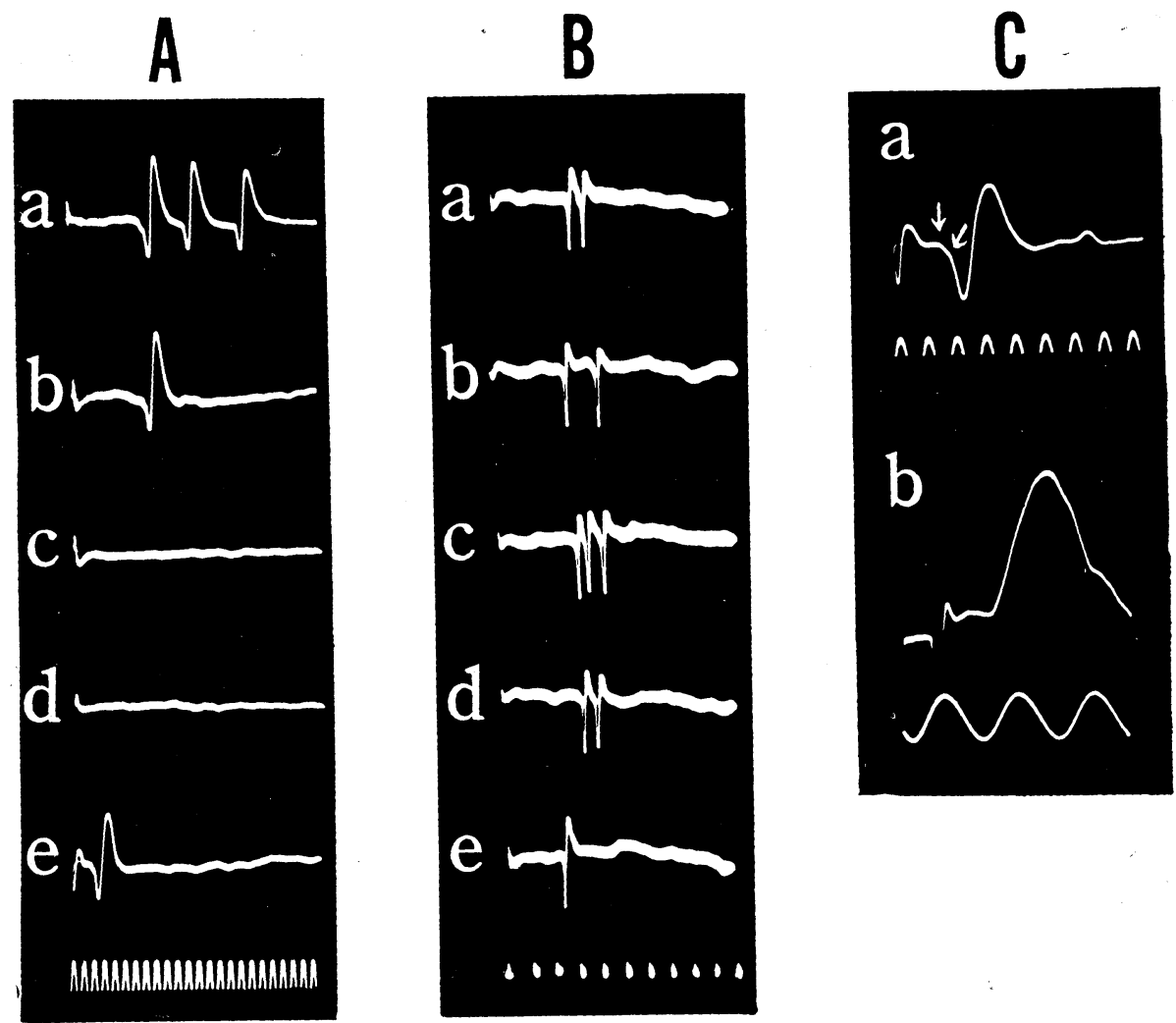

FIG. 2. Patterns of response of VB neurons to peripheral and medial lemniscal stimulation. A : a "specific" type of neuron, B: a "non-specific" type of neuron. In A and B, single shock was applied at the onset of each trace to ulnar (a), superficial redial (b), tibial (c) and superficial peroneal nerves (d), and medial lemniscus (e). Ca: The same as Ae, but with fast sweep. $\mathrm{Cb}$ : An antidromic response evoked by stimulation of the VB complex and picked up with the bipolar electrodes used for medial lemniscus stimulation. Time: $1 \mathrm{msec}$. for $\mathrm{A}$ and $\mathrm{C}, 10$ msec. for $B$. In this and the following figures monopolar records are negative upwards.

either to the contralateral radial nerve, or the contralateral ulnar nerve, but not both. These two types (130.units) we have called "specific" VB units. The remaining 39 units of the 169 tested had much larger apparent receptive fields, i. e., they responded not only to contralateral forelimb nerve stimulation, but also to contralateral hindlimb and ipsilateral forelimb (FIG. 2B). These we have labelled "non-specific" somatosensory units.

(2) Medial lemniscal stimulation. Single shock stimulation of the contralateral medial lemniscus at the level of the dorsal column nuclei induced "specific" unit discharges as in FIG. 2Ae, also shown with fast sweep in FIG. $2 \mathrm{Ca}$. The latencies of the small positive deflection (first arrow) and of the 
steep downward stroke (second arrow) were 1.5 and 1.9 msec. respectively in this case. Antidromically measured conduction times in the medial lemniscus were $0.8-0.9 \mathrm{msec}$. (FIG. $2 \mathrm{Cb}$ ). The difference between these two delays indicated that VB spikes were frequently initiated less than $1.0 \mathrm{msec}$. after arrival of the lemniscal impulse.

Medial lemniscal stimulation at higher intensities often caused repetitive responses of the specific VB neuron.

(3) Antidromic stimulation. Half of the "specific" neurons tested responded antidromically to stimulation of a restricted area of the postcruciate gyrus. The criteria defining antidromic excitation will be described in detail in the next section.

Almost all "non-specific" somatosensory units were excited by strong lemniscal stimulation, though the responses were inconstant. Sometimes no spikes were produced, and sometimes one or two were produced with long latencies (FIG. 2Be). Antidromic responses to cortical stimulation were also produced in some of these units. Nevertheless, units of this "non-specific" type (as regards peripheral receptive field) were all discarded in the present study.

Some of the specific VB neurons included in these experiments were identified only by peripheral and medial lemniscal stimulation. The responses of these neurons to various central stimuli (detailed below) were the same as those of neurons which satisfied the three criteria discussed above.

When a given VB unit spike evoked by peripheral nerve stimulation was first detected on advancing the microelectrode, it usually was of negative monophasic shape, with or without an initial slight positivity, and often superimposed on a small negative field response. As the electrode was advanced, positive as well as negative phase enlarged. Later the amplitude of the positive phase increased, an inflection appeared on the positive stroke, and the negative phase decreased. These changes are similar to those which have been observed with lateral geniculate neurons ${ }^{5)}$. The large positive spike usually was not maintained for a long enough time to test the effect of stimulations applied to all relevant cortical areas. Moreover, as the positive spike increased in amplitude, it responded to cortical inhibition (described below) less well than the smaller negative spikes. This may have been due to partial deterioration of the neuron. For this reason and because the positive spikes were relatively inconstant, small negative or positive-negative spikes less than $2 \mathrm{mV}$ in amplitude were tested in most of the present experiments.

2. Effects of cortical stimulation on VB neurons.

a. Early excitation following cortical stimulation.

Antidromic excitation. FIG. 3 shows examples of antidromic responses of 

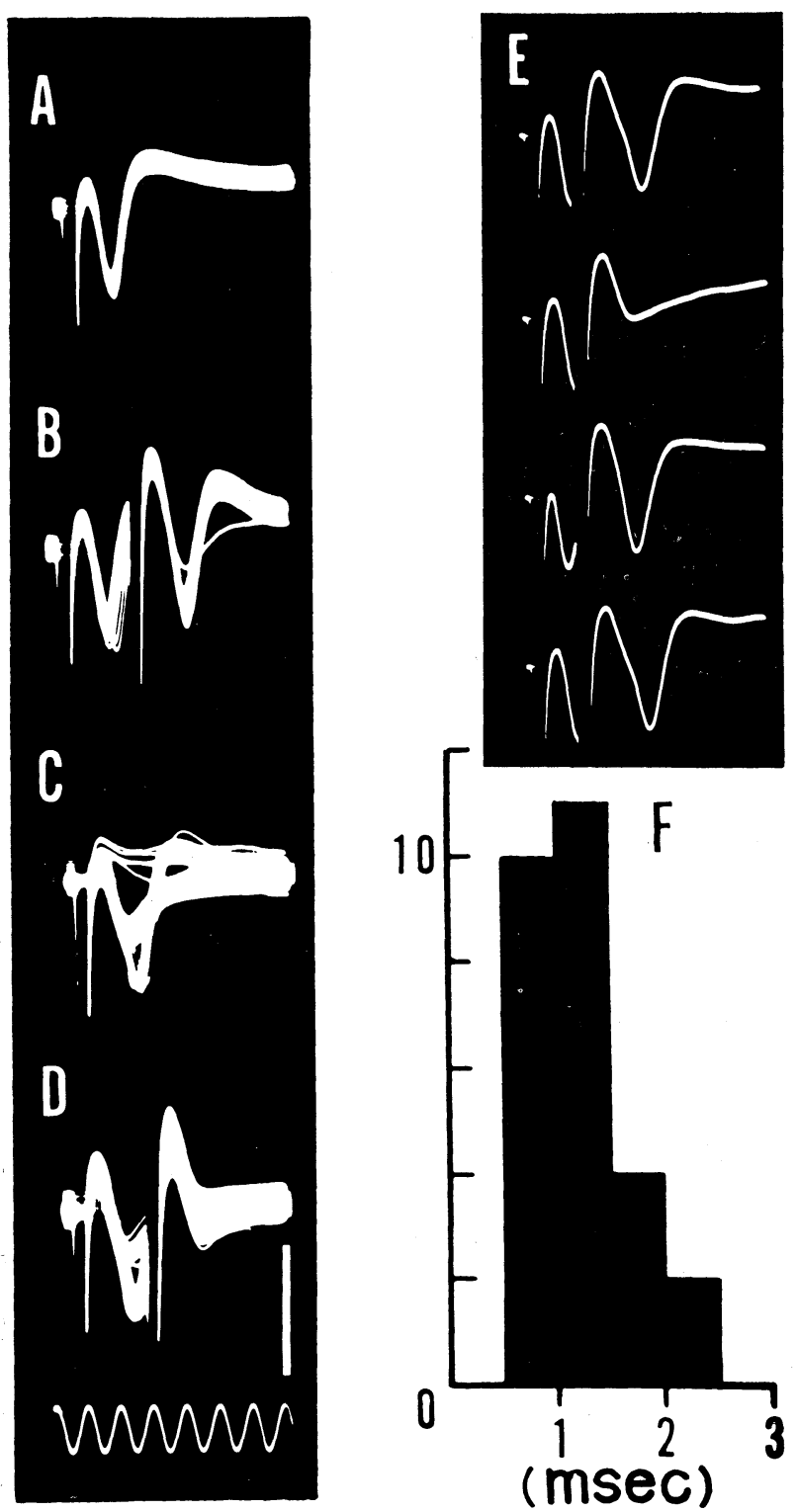

FIg. 3. A-E: Antidromic excitation of a specific VB neuron to postcruciate cortical stimulation. In A-D, about 20 sweeps were superimposed. A : $10 /$ sec. ; B : 10/sec. double shocks with 2.2 msec. interval; C: 100/sec.; D : $100 / \mathrm{sec}$. double shocks with $2.2 \mathrm{msec}$. interval; E: $1 / \mathrm{sec}$. double shocks with $1.4 \mathrm{msec}$. interval. Stimulation current was $0.8 \mathrm{~mA}$ in each case. Voltage calibration : $5 \mathrm{mV}$, Time : $1 \mathrm{msec}$. F : Histogram of latencies of 27 specific VB neurons to antidromic stimulation of the postcruciate cortex. Each value is the average of 10 responses. 
a "specific" VB neuron which responded only to superficial radial nerve stimulation. Antidromic excitation by means of $10 / \mathrm{sec}$. shocks to a restricted area in the lateral part of the postcruciate gyrus showed constant latency (FIG. 3A). Double shocks at $2.2 \mathrm{msec}$. interval excited the neuron with almost no blocking of the response to the second shock (FIG. 3B). With double shocks at $1.4 \mathrm{msec}$. interval (FIG. 3E), the second spikes showed a prominent inflection, and sometimes appeared as small potentials without fully developed spikes. These two component potentials probably correspond to the $\mathrm{A}$ and $\mathrm{B}$ components of FUORTES et al..$^{9)}$ or the IS (NM) and SD spikes of BROcK et al. ${ }^{6)}$. The variability of the latency of the $\mathrm{B}$ component never exceeded $0.5 \mathrm{msec}$. for a given unit. When $100 / \mathrm{sec}$. repetitive stimulation was applied for a longer period, fractionation of the response into two components was prominently observed (FIG. 3C). Blocking of the B component was seen in every succeeding spike with $100 / \mathrm{sec}$. double shock stimulation with $2.2 \mathrm{msec}$. intervals (FIG. 3D). The results of FIG. $3 \mathrm{C}$ and $3 \mathrm{D}$ may be partially due to antidromic inhibition developed in the VB neuron by cortical repetitive stimulation. This will be discussed later.

On the basis of these results, the following two criteria were adopted as indicating antidromic excitation of cortically evoked VB responses which were usually small negative or positive-negative spikes. (i) Constant Latency (variability less than $0.3 \mathrm{msec}$.) with $10 / \mathrm{sec}$. cortical stimulation. (ii) Prolongation of the latency of less than $0.5 \mathrm{msec}$. in the succeeding spike when stimulated with double shocks with $1.4-2.0$ msec. intervals.

The intensity of cortical stimulation necessary to evoke these antidromic responses was usually $0.8-3.0 \mathrm{~mA}$. At higher intensities stimulation of a number of the laterally arranged postcruciate electrodes ( $1.5 \mathrm{~mm}$. apart) evoked the response. As the strength of stimulus was decreased, the cortical area from which the antidromic response was obtained decreased until with minimal stimulus the effective cortical focus was restricted to one or two electrodes.

The latencies of antidromic responses to cortical stimulation for 27 specific VB neurons are shown in the histogram of FIG. 3F. The latencies ranged from 0.66 to $2.40 \mathrm{msec}$. Assuming a conduction distance of $20 \mathrm{~mm}$, these latencies correspond to conduction velocities of $8.3-30.3 \mathrm{~m} / \mathrm{sec}$.

Trans-synaptic excitation. FIG. 4Aa shows the response of a specific VB neuron to contralateral ulnar nerve stimulation. When the postcruciate cortex was stimulated at $10 / \mathrm{sec}$, the antidromic response of this neuron was followed by some late responses (FIG. 4Ab). The latencies of these late responses varied considerably. FIG. $4 \mathrm{Ba}$ shows another example of a peripherally evoked VB unit. This neuron also responded to cortical stimulation at variable latencies and with variable numbers of spikes, but there were no antidromic responses (FIG. 4Bb). Such responses will be called "trans-synaptic excitation". The histogram of FIG. $4 \mathrm{C}$ summarizes latencies of trans-synaptic first 


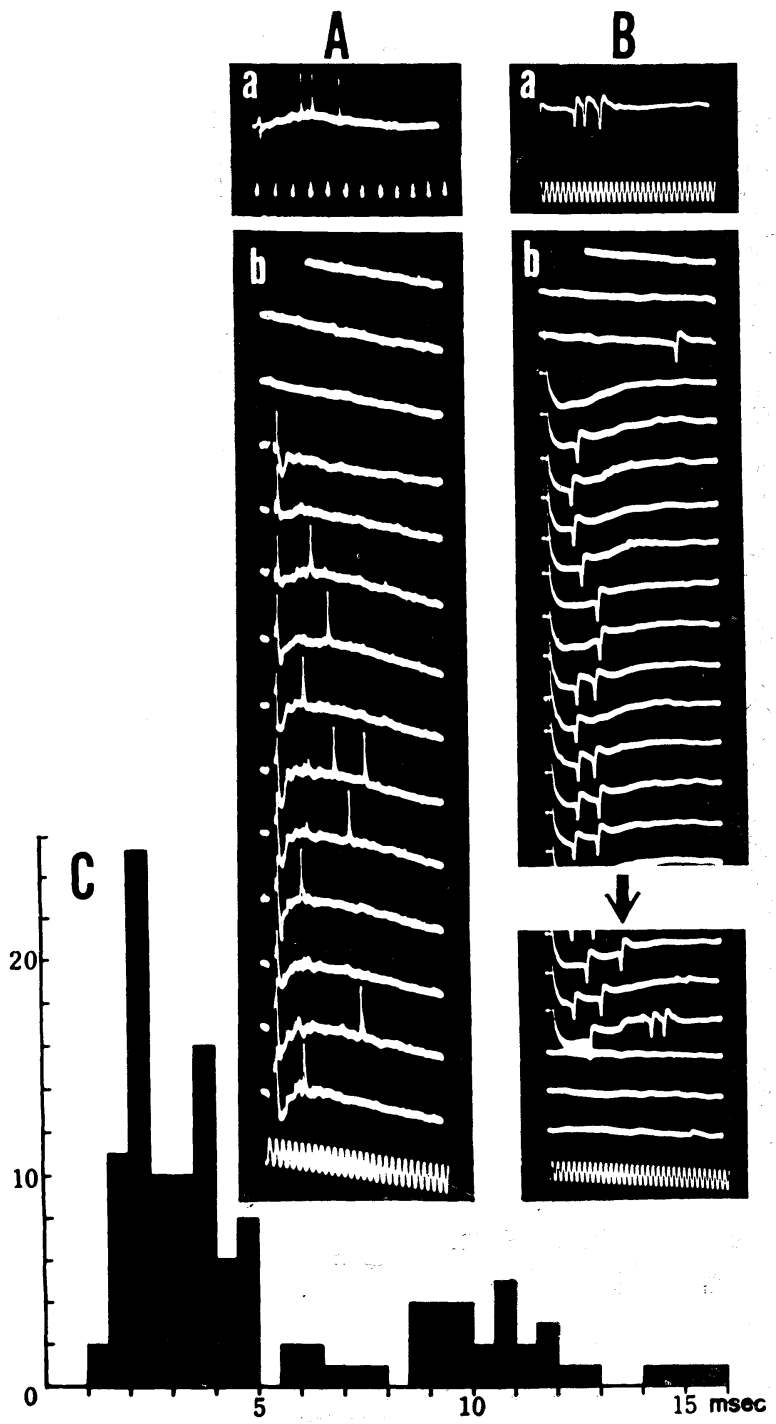

FIG. 4. Trans-synaptic excitation of VB neurons by postcruciate cortical stimulation. $A$ and $B$ were different neurons. In each of them, a : ulnar nerve stimulation, $b$ : repetitive stimulation of the cortex at $10 / \mathrm{sec}$. began with the fourth sweep. Time: 5 msec. for Aa and $1 \mathrm{msec}$. for the rest. C: Histogram of latencies of trans-synaptic first responses to postcruciate stimulation. Five or 8 latencies are plotted for each of $18 \mathrm{VB}$ neurons. 
responses to cortical single stimulation for $18 \mathrm{VB}$ neurons. In this histogram latencies were not used if the responses were accompanied by antidromically excited spikes.

Some neurons were spontaneously active, discharging at $3-10 / \mathrm{sec}$. or more. These neurons were not included in the above, because of the possibility of confusion between evoked and spontaneous activity.

About one third of the specific VB neurons tested showed trans-synaptic excitation on stimulation of a restricted area of the postcruciate cortex. The active cortical focus, from which trans-synaptic excitation was obtainable, always included the focus from which antidromic responses were obtained. The former was usually $1.5-3.0 \mathrm{~mm}$. wider than the latter, i.e., the transsynaptic response was obtainable from one or two more of the laterallyarranged postcruciate electrodes than was the antidromic response. It was often impossible to obtain trans-synaptic responses on stimulation of the center of the cortical area from which antidromic responses were obtained, only antidromic responses being obtainable from such points. In Fig. 5Ba, for example, antidromic responses were seen in almost all of about 20 super-
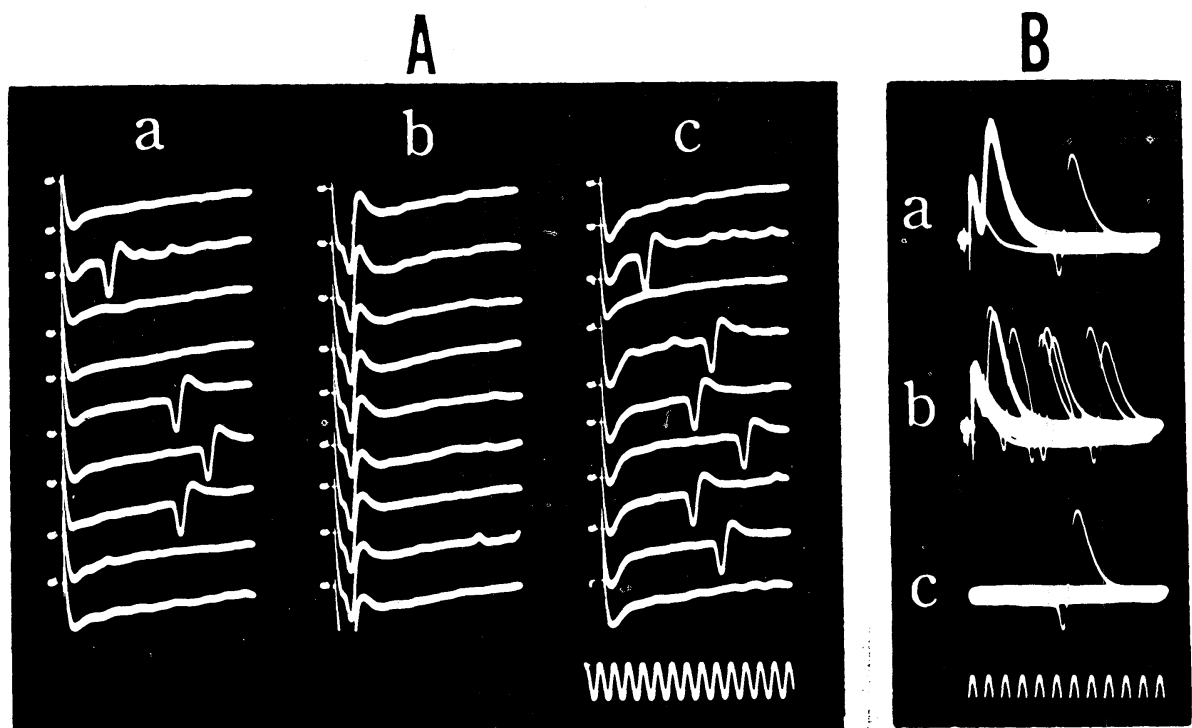

FIG. 5. Interaction between antidromic and trans-syraptic excitation of VB neurons by postcruciate cortical stimulation. Neuron "A" was antidromically excited by one electrode $(\mathrm{Ab})$, and trans-synaptically excited by an electrode 1.5 $\mathrm{mm}$. medial (Aa) and by another $3 \mathrm{~mm}$. lateral (Ac). Successive records of $10 / \mathrm{sec}$. stimulation from up to down. Stimulation current was $1.8 \mathrm{~mA}$ in each record. Neuron "B" was stimulated at $2.1 \mathrm{~mA}$, which was near threshold for antidromic excitation of this neuron. Superimposed records of about 20 sweeps at $8 / \mathrm{sec}$. $\mathrm{Ba}$ : mostly antidromic responses, $\mathrm{Bb}$ : many trans-synaptic responses, $\mathrm{Bc}$ : spontaneous discharge. Time: $1 \mathrm{msec}$. 
imposed traces, with only rare delayed spikes. When antidromic responses happened to be reduced, many trans-synaptically evoked spikes were found (FIG. 5Bb). These delayed spikes were confirmed to be true "responses" to cortical stimulation by comparing with spontaneous discharges of the same neuron (FIG. 5Bc). These observations suggest that lack of trans-synaptic excitation (FIG. 5Ab), as compared with the cortical regions on either side (FIG. 5Aa and c), may be due to the depression associated with concomitant antidromic firing. This may also account for the frequent observation that stimulation of a given cortical electrode produced only trans-synaptic responses while stimulation of an adjacent electrode $(1.5 \mathrm{~mm}$. distant) produced only antidromic responses (FIG. 9D and 9E). Brief trains of repetitive cortical stimuli were generally more effective than single shocks in producing transsynaptic activation of VB neurons. After acute cortical ablation, stimulation of the exposed white matter of the postcruciate gyrus resulted in comparable observations.

In half of the specific VB neurons which were trans-synaptically excited by cortical stimulation, no antidromic responses were elicited. It is probable that VB neurons lacking antidromic responses may be interneurons concerned with somatosensory transmission, though some of them might respond antidromically to more extensive cortical stimulation.

b. Delayed inhibition following cortical stimulation.

Cortical area producing inhibition of VB neurons. Stimulation of the surface (in the case of FIG. 6C of acutely exposed white matter) at locus 4 (large dot) evoked antidromic responses in a "specific" VB neuron. This neuron's response to lemniscal, single-shock stimulation is seen in FIG. 6Aa. Fifty msec. after a single conditioning shock to locus 6 (cf. FIG. 6C), the latencies of spikes to test lemniscal shocks were prolonged without great change in the latencies of the small positive potential indicated by the arrow in FIG. $6 \mathrm{Ab}$. When the conditioning stimulus consisted of 6 pulses at $500 / \mathrm{sec}$., the prolongation of latency was more striking (FIG. 6Ac). Moreover, fully developed spikes were abolished in some traces, though the small positive deflections, indicated by arrow, remained almost unchanged. This prolongation of latency and reduction in number of evoked spikes are undoubtedly manifestations of inhibition rather than of occlusion or of refractoriness, because neither antidromic nor trans-synaptic responses were evoked by the conditioning shocks alone. Similar inhibition was also produced by stimulation of the intact postcruciate cortex, but not by stimulation in the precruciate area. These inhibitory effects from the postcruciate area were demonstrated in almost all of the specific VB neurons tested.

In order to localize the postcruciate cortical fields producing this delayed inhibition, conditioning shocks were applied to each of loci 1 through 7 of 


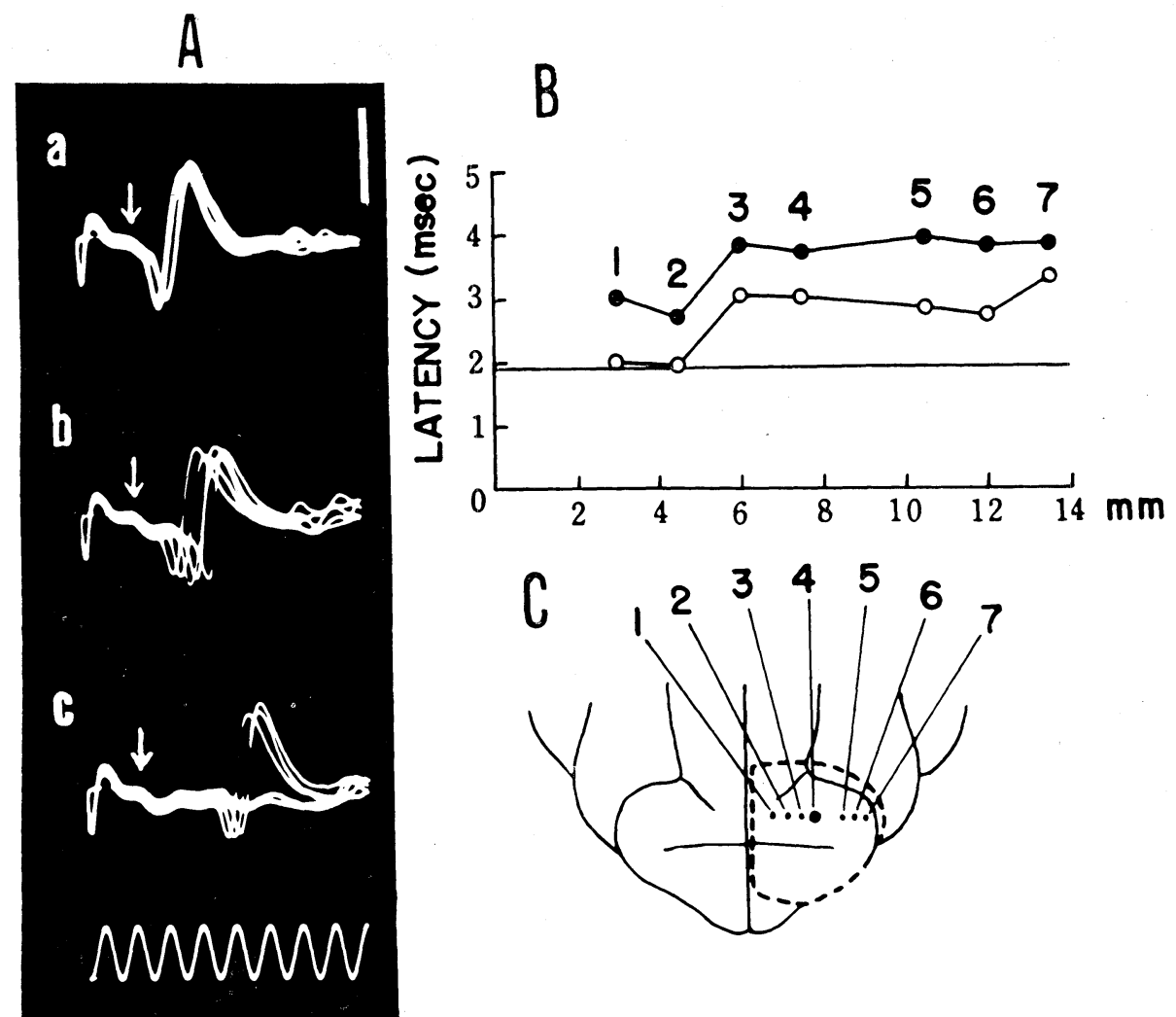

Fig. 6. Delayed inhibition of VB neuron by postcruciate stimulation. A : Effects of cortical conditioning stimulation applied to locus 6 of C, $50 \mathrm{msec}$. prior to medial lemniscal test stimulation. (a) control test response, (b) after cortical single shock, (c) after 6 shocks at 500/sec. Voltage calibration: $2 \mathrm{mV}$. Time: 1 msec. B: Plots showing the effects on latency of one cortical conditioning shock and of six shocks (at $500 / \mathrm{sec}$ ) at the cortical loci shown in C. Open circles: single shock conditioning. Filled circles: 6 shock conditioning. Each point was the average of 8 responses, tested at $1 / \mathrm{sec}$. Conditioning-test interval was $50 \mathrm{msec}$. in every case. Abscissa shows the distance of each electrode from the mid-sagittal line. Horizontal line indicates the control value of latency to lemniscal test shock (1.9 msec.). C : Diagramatic representation of the cortical position of stimulating electrodes. The broken line circumscribes the area of cortex sucked off at the beginning of the experiment.

FIG. 6C. In FIG. 6B are plotted mean latencies of spikes evoked by $1 / \mathrm{sec}$. lemniscal stimulation $50 \mathrm{msec}$. after single-shock cortical conditioning (open circles) and after 6 shocks at $500 / \mathrm{sec}$. (filled circles). In this instance, antidromic responses were evoked by stimulation of locus 4 , but none of the other cortical stimulating sites gave rise to either antidromic or trans-synaptic responses, even with six repetitive pulses. Not only did repeating the condi- 
tioning stimulus prolong latencies, but it also extended the inhibitory field (FIG. 6B, filled circles). The area of the acutely exposed white matter which exerted an inhibitory influence on a given VB neuron was not significantly different from that of the intact cortex.

In 21 of 25 specific VB neurons tested, the cortical focus for antidromic or trans-synaptic activation of the neuron was surrounded by a larger cortical field whose stimulation produced the kind of delayed inhibition shown in FIG. 6. A stimulus of minimal intensity, which produced antidromic and/or transsynaptic VB neuronal responses from a cortical area extending not more than $3 \mathrm{~mm}$. along the postcruciate gyrus, usually produced delayed inhibitory influences on the same neuron for at least $7.5 \mathrm{~mm}$. along the gyrus.

In the other 4 of these 25 neurons, the cortical fields responsible for early excitation and the fields giving delayed inhibition were essentially co-extensive. In these four instances the inhibitory effects were very weak, even
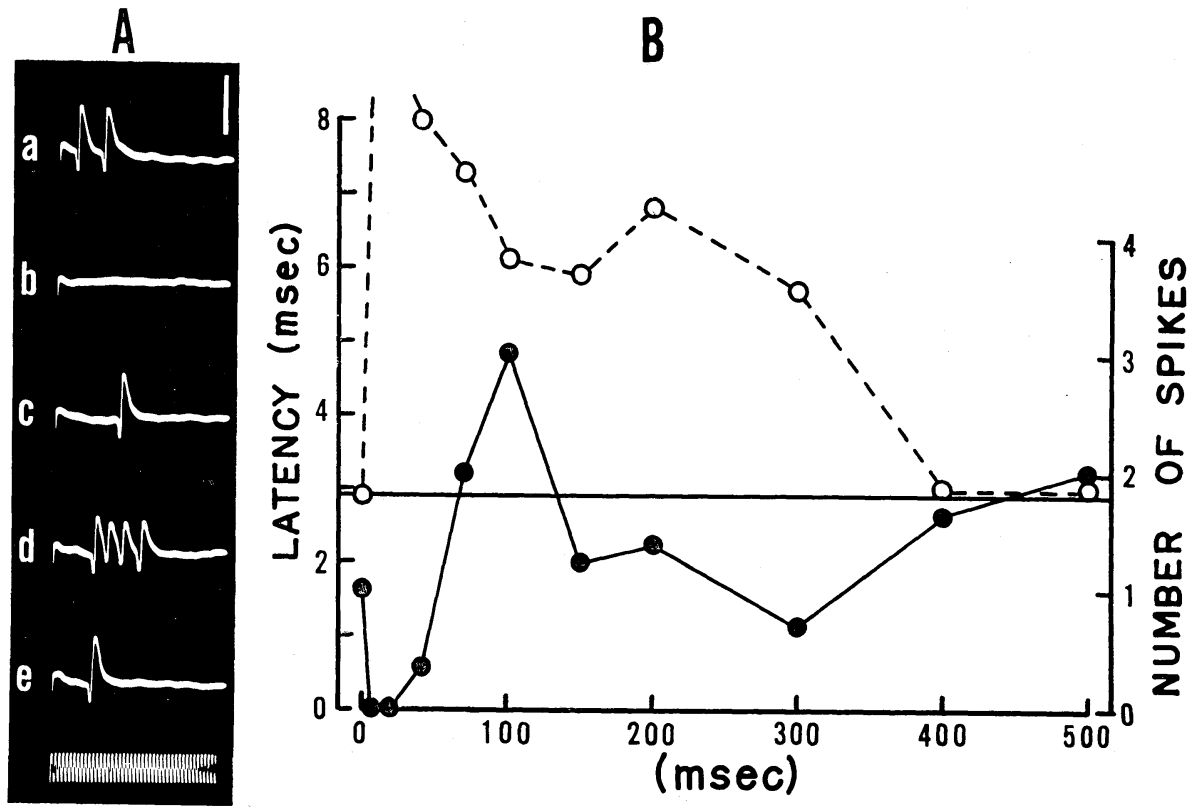

FIG. 7. Time course of delayed inhibition on VB neurons. A : Actual responses at various conditioning-test intervals. Conditioning stimulation applied to the postcruciate gyrus was 6 pulses at $500 / \mathrm{sec}$. and $2.1 \mathrm{~mA}$. (a) control response to medial lemniscal stimulation. Conditioning-test intervals were: (b) $20 \mathrm{msec}$, (c) $100 \mathrm{msec}$, (d) $150 \mathrm{msec}$, (e) $400 \mathrm{msec}$. Voltage calibration : $3 \mathrm{mV}$. Time: $1 \mathrm{msec}$. $\mathrm{B}$ : Diagramatic representation of effects of postcruciate conditioning (6 shocks at $500 / \mathrm{sec}$. and $1.8 \mathrm{~mA}$ ) on another VB neuron. Latencies to medial lemniscal test shock are indicated by open circles with the scale on left ordinate. Numbers of evoked spikes are shown by filled circles with the scale on right ordinate. Abscissa shows conditioning-test intervals. The horizontal line represents the control value both of latency and evoked spike count. 
with stimulation of the center of the inhibitory cortical areas. The reasons for this are unknown.

Discharge pattern in the course of inhibition. FIG. 7Aa shows the response of a specific VB neuron to a test lemniscal shock. Ten to $75 \mathrm{msec}$. after cortical conditioning with 3 pulses at $500 / \mathrm{sec}$., the response was completely inhibited (FIG. 7Ab). One hundred msec. after conditioning, latency was prolonged and the number of spikes decreased over the control (FIG. 7Ac). These effects are similar to those illustrated in FIG. 6Ab and c. When, however, the conditioning stimuli were applied $150-300 \mathrm{msec}$. prior to the test shock, the number and frequency of evoked spikes were greatly increased, even though the latency remained prolonged (FIG. 7Ad). Four hundred to $500 \mathrm{msec}$. after conditioning, the number of spikes again decreased (FIG. 7Ae). Fig. 7B is a plot of the responses of another VB neuron. In this instance the prolongation of latency was observed from 10 to $300 \mathrm{msec}$. after cortical conditioning, while the increase in number of spikes was observed only at $100 \mathrm{msec}$. The precise time course of these effects not only depended on the strength and number of conditioning stimuli, but also varied from neuron to neuron.

Such characteristic cortical conditioning effects were observed in about half the specific VB neurons tested. In others, the inhibitory effect was not observed for more than 50-100 msec., and the peculiar prolongation of latency with increased spiking activity did not appear.

\section{Effect of pyramidal stimulation on $V B$ neurons.}

Restricted pyramidal excitation monitored by cortical response. Responses evoked in the cortex were used to distinguish pure pyramidal excitation from combined pyramidal and lemniscal excitation. FIG. 8A shows the response evoked in the lateral part of the postcruciate gyrus by weak stimulation $(0.4$ $\mathrm{mA}$ ) of the pyramid at the border between pons and trapezoid body, rostrally to pyramidal transection. An initial positive deflection and a later small positive wave were observed. These two positive deflections will be designated $a$ and $\beta$ responses, following the suggestion of JABBUR and TowE ${ }^{17)}$. The initial deflection $(a)$ followed $500 / \mathrm{sec}$. pyramidal stimulation without visible change. When a stronger stimulus $(1.5 \mathrm{~mA})$ was applied with the same electrodes, the $a$ response became larger and was followed by a late positive steep deflection, the $b$ response (FIG. 8B). When the surface of the pyramid was stimulated $3 \mathrm{~mm}$. caudally to the pyramidal transection, $b$ and slight $c$ or $d$ responses were evoked without any visible $a$ potential (FIG. $8 \mathrm{C}$ ), or with a very faint $a$ potential. If the $a-\beta$ and $b-d$ components of these cortical responses can be attributed respectively to excitation of pyramidal fibers and deeper structures including lemniscal fibers ${ }^{17,22)}$, the responses of FIG. 8 confirm the histological observation (cf. FIG. 8D) that almost all of the pyramidal fibers are transected, most lemniscal fibers remaining intact. 

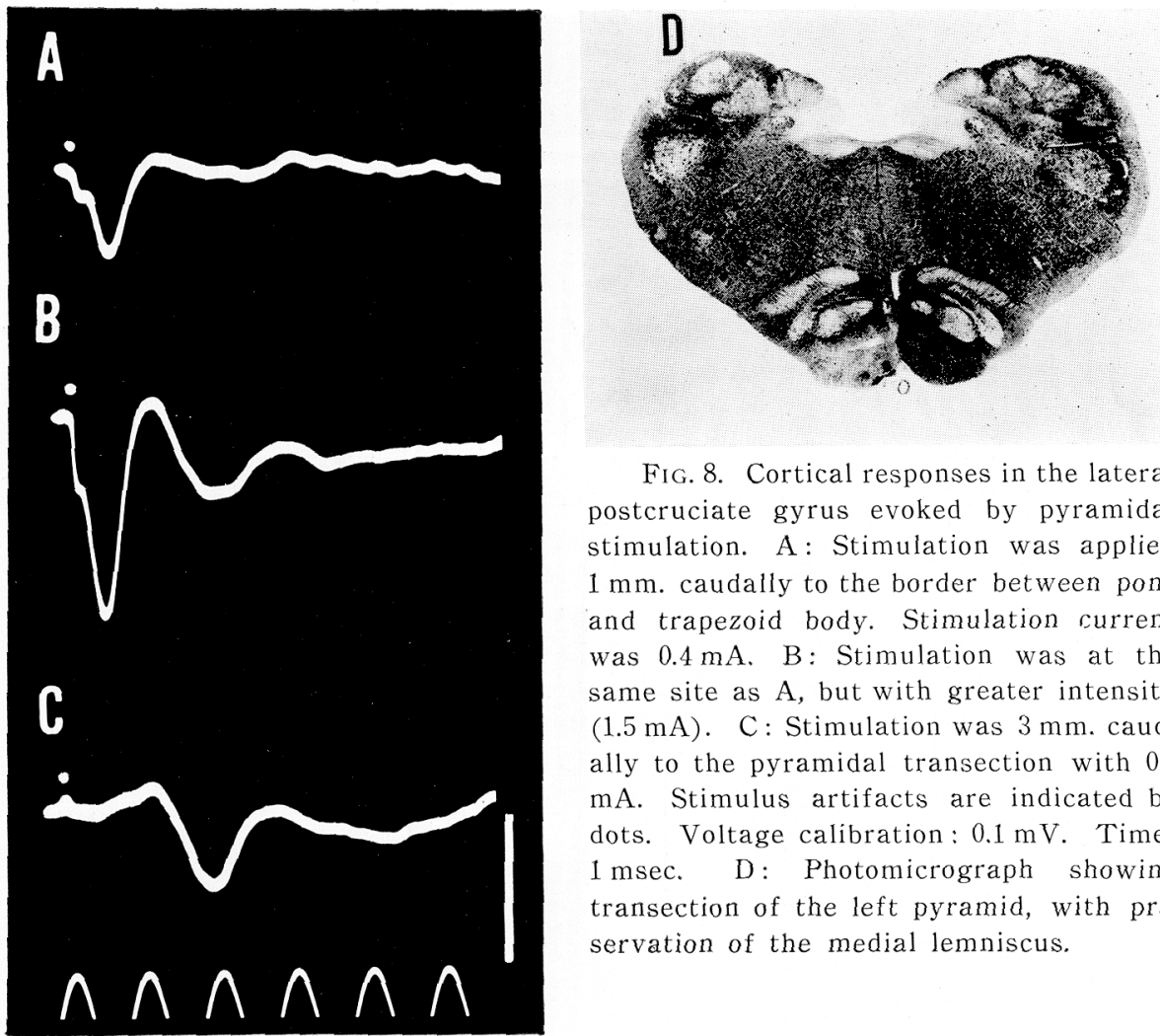

FIG. 8. Cortical responses in the lateral postcruciate gyrus evoked by pyramidal stimulation. A: Stimulation was applied $1 \mathrm{~mm}$. caudally to the border between pons and trapezoid body. Stimulation current was $0.4 \mathrm{~mA}$. B: Stimulation was at the same site as $\mathrm{A}$, but with greater intensity $(1.5 \mathrm{~mA})$. C: Stimulation was $3 \mathrm{~mm}$. caudally to the pyramidal transection with 0.4 $\mathrm{mA}$. Stimulus artifacts are indicated by dots. Voltage calibration: $0.1 \mathrm{mV}$. Time: 1 msec. D: Photomicrograph showing transection of the left pyramid, with preservation of the medial lemniscus.

The effects of pyramidal stimulation on specific VB neurons were studied using stimuli which produced only $a$ and $\beta$ cortical responses, as in Fig. 8A. The intensity of stimulation was carefully adjusted to make the amplitude of the $a$ response less than 50-60\% of maximal. This intensity was usually less than $40 \%$ of the threshold of the late $b$ or $d$ responses.

Pyramidal excitation of VB neurons. FIG. 9 shows the various responses of a specific $\mathrm{VB}$ neuron with a typical response pattern. It responded to ulnar nerve shock (FIG. 9A), was antidromically excited by stimulation at one cortical locus (FIG. 9D), and trans-synaptically excited by stimulation at an adjacent locus (FIG. 9E). This neuron was also excited by a pyramidal single shock (FIG. 9B) of intensity carefully controlled by monitoring the cortical $a$ response, as discussed above. When this pyramidal stimulation was applied at $10 / \mathrm{sec}$, the neuron responded to the stimuli with variable latencies (FIG. 9C). In some of the sequential traces shown, no spikes were evoked. (e. g., traces 5, 7, 10 and 16 of FIG. 9C), and occasionally multiple spikes were evoked (trace 14). Pyramidal stimulation by brief repetitive shocks was more effective than single shocks in evoking VB neuron responses. These patterns of 

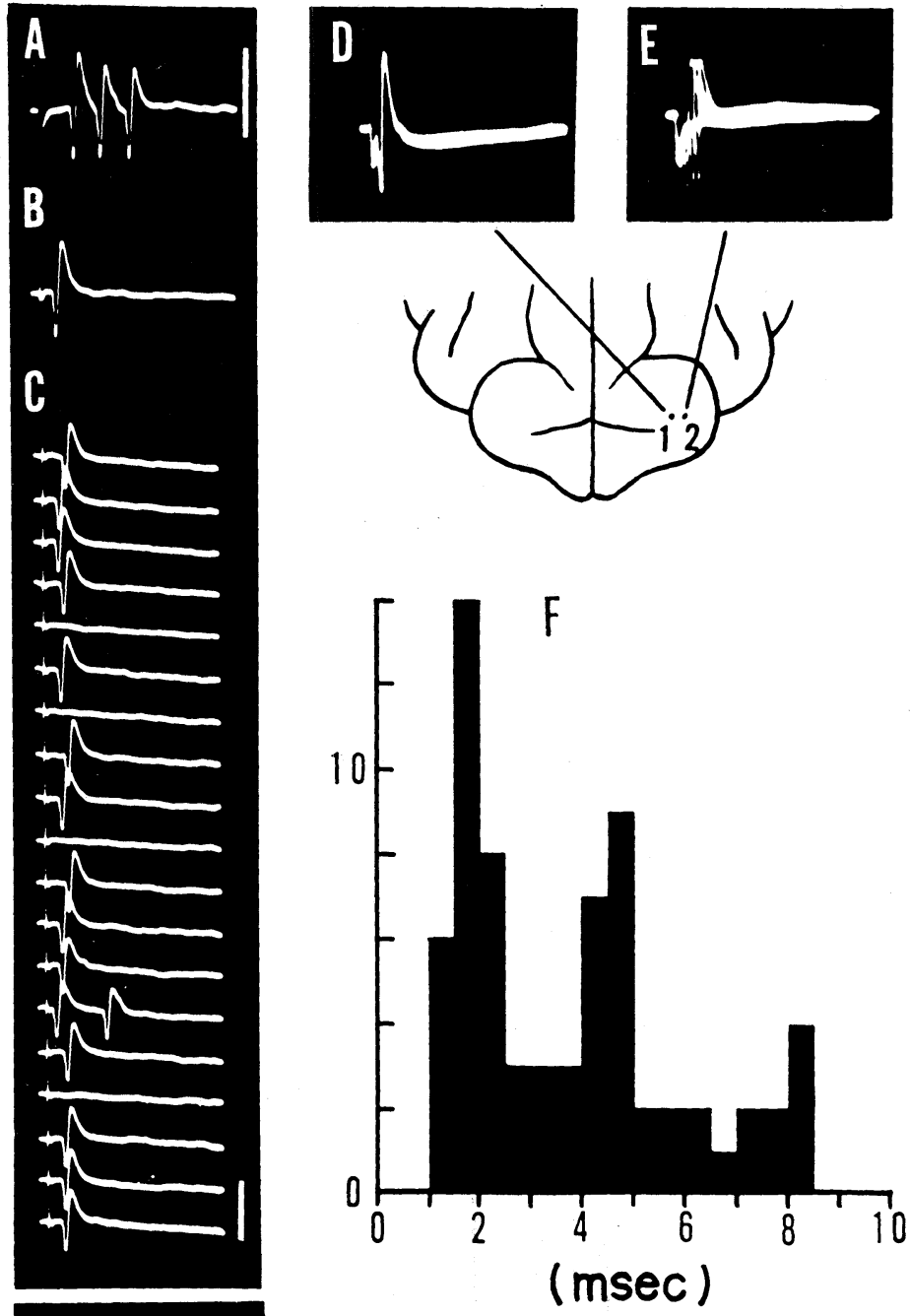

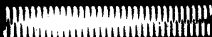

FIG. 9. Trans-synaptic excitation produced by pyramidal stimulation. A-E : Responses of a single VB neuron to various stimulations. A : Ulnar nerve stimulation. B: Pyramidal single stimulation, applied ipsilaterally and rostrally to the pyramidal transection. $C$ : Successive responses to pyramidal stimulation at $10 / \mathrm{sec}$. D : Antidromic excitation by stimulation of cortical locus 1. E: Trans-synaptic excitation by stimulation of locus 2. Both $D$ and $E$ show five superimposed traces, applied at $1 /$ sec. Voltage calibration: $3 \mathrm{mV}$. Time: $1 \mathrm{msec}$. F : Histogram showing latencies of first responses to pyramidal stimulation. Eight or nine values are plotted from each of $8 \mathrm{VB}$ neurons. 
response to pyramidal stimulation were quite similar to the patterns of transsynaptic response to cortical stimulation, as in FIG. $4 \mathrm{Bb}$.

Of 52 specific VB neurons tested by restricted pyramidal stimulation, 15 were excited. The latencies of response to pyramidal single stimulation of 8 of these neurons are plotted in the histogram of FIG. 9F.

Delayed inhibition of $V B$ neurons. Pyramidal stimulation also caused delayed effects in specific VB neurons. In about one third of the neurons tested, the latencies between lemniscal test shock and neuronal spikes were prolonged by pyramidal conditioning applied $20-40 \mathrm{msec}$. prior to the test shock. This inhibitory effect, however, was less than with cortical condition. ing, and usually did not last more than $50-70 \mathrm{msec}$. after the pyramidal conditioning stimulus.

\section{Effect of chronic cortical ablation.}

Five cats had pericruciate cortical ablations 22-30 days before study. The responses to pyramidal stimulation were observed in the exposed white matter of the postcruciate gyrus in these preparations (FIG. 10A). Strong pyramidal single-shock stimulation (4.2 mA) evoked typical $b, c$ and $d$ responses (FIG. 10Aa-monopolar recording). With bipolar recording (FIG. 10Ab) the latency of the initial deflection was $1.4 \mathrm{msec}$. With acute cortical ablation the latency of the $a$ response was only $0.6 \mathrm{msec}$. (FIG. 10Bb). This difference was consistent, indicating lack of $a$ response in the chronically decorticated preparation. Of similar significance, no specific VB neuron was excited by stimulation of the medullary pyramid at intensities below the threshold of the cortical $b$ response in these animals. These results were interpreted as meaning that the descending cortico-pyramidal fibers are incapable of impulse conduction in the chronically decorticated cat.

In these preparations, the effect of stimulation of the exposed white matter of the postcruciate gyrus was observed in 50 specific VB neurons. Antidromic responses were evoked in about half the neurons tested. This ratio was the same as with the intact cortex as mentioned above. Trans-synaptic responses were not found. Delayed inhibition was observed in most of the neurons, with time course and size of effective field similar to the intact preparations. The results in one such preparation are plotted in FIG. 10C. The inhibitory influence on the neuron was produced by stimulation of the postcruciate field for $7.5 \mathrm{~mm}$. along the gyrus. The prolongation of latency, the alternate decrease, increase and then again decrease in number of evoked spikes were very similar to the pattern observed with intact cortex (compare FIG. 7B). 

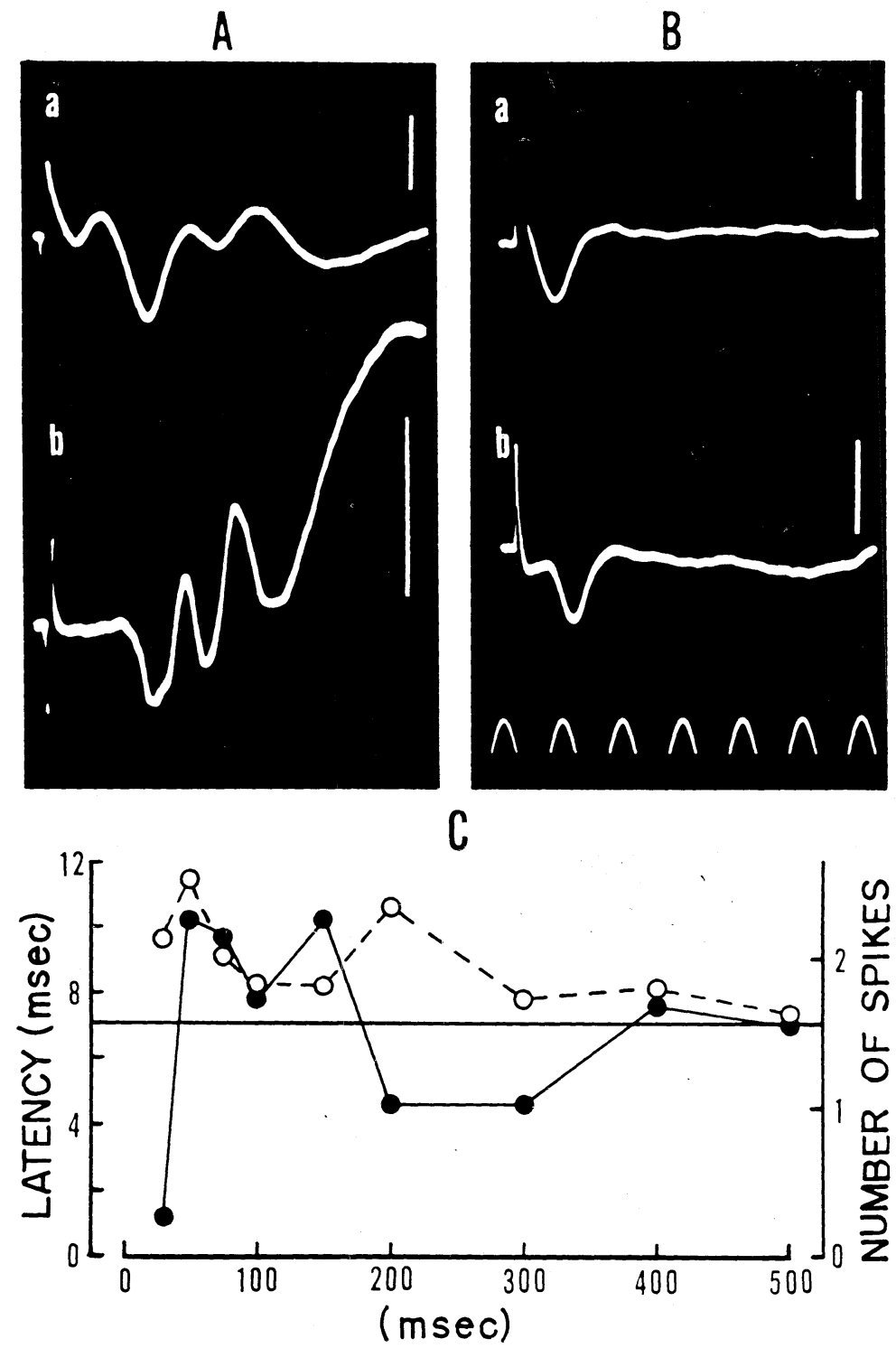

Fig. 10. A and B: Responses evoked in the exposed white matter of the lateral postcruciate gyrus by stimulation of the ipsilateral pyramid. In the chronic preparation " A", stimulation was $4.2 \mathrm{~mA}$, undoubtedly high enough to affect the medial lemniscus; in the acute preparation "B", it was $0.4 \mathrm{~mA}$. Aa and $\mathrm{Ba}$ : Monopolar recordings from the surface of the exposed white matter. $\mathrm{Ab}$ and $\mathrm{Bb}$ : Bipolar recordings with vertically oriented electrodes, one $2 \mathrm{~mm}$. into the white matter, the other on the surface. Voltage calibration: $0.1 \mathrm{mV}$. Time: $1 \mathrm{msec}$. C: Time course of conditioning of a VB neuron by postcruciate stimulation in a chronically decorticated cat. Conditioning stimuli were 6 pulses at $500 / \mathrm{sec}$. and 1.8 $\mathrm{mA}$. Arrangement of the graph is same as FIG. 7B. 


\section{DISCUSSION}

The experimental results obtained in this study indicate that many VB neurons are excited by stimulation of restricted areas of the postcruciate gyrus of the cat, with variable numbers of evoked spikes and variable latencies. It has been suggested by BuRNs $^{8)}$ that antidromic activation can produce late repetitive responses of the neuron, and that they represent afterdischarges due to differential repolarization in other parts of the neuron following invasion of an antidromic impulse into the soma. In the present experiments, however, late repetitive responses have been demonstrated in the absence of antidromic inputs (FIG. 4Bb and Fig. 5Aa and c). Hence, it may reasonably be concluded that the responses to cortical stimulation with variable latencies result from trans-synaptic excitation.

Latencies of trans-synaptically excited unit responses following stimulation of the exposed white matter in the acutely decorticated animal did not differ from latencies following stimulation of the intact cortex. It is therefore concluded that the response delays are due to synaptic mechanisms within subcortical structures, including the thalamus itself.

There yet remain two possibilities, that this trans-synaptic action is orthodromic (corticofugal), or antidromic (via collaterals from corticopetal fibers). The lack of trans-synaptic response to postcruciate stimulation in the chronically decorticated animal lessens the latter (antidromic) possibility. On the other hand, the anatomically demonstrated corticofugal fibers from postcruciate gyrus to VB nucleus ${ }^{421)}$ support the idea that this trans-synaptic excitation may be caused by orthodromic impulses from somatosensory cortex.

The cortical potentials evoked by stimulation of the medullary pyramid have been studied in detail by other ${ }^{24,25,33}$. Selective excitation of the pyramidal tract is difficult because of the proximity of the medial lemniscus. LANDAU ${ }^{25)}$ has asserted "significant contamination by dromic impulses in the medial lemniscus can be avoided only by severing the brainstem except for the peduncle." As expected, it has been quite difficult in the present experiments to isolate antidromic cortical responses from orthodromic contamination, even with fine pyramidal electrodes, when applied to the middle or caudal parts of the medullary pyramid.

JABBUR and TOWE ${ }^{17)}$, however, have established criteria which can be used to identify the effects of pyramidal stimulation free of lemniscal contamination. They demonstrated that pyramidal stimulation of the ponto-medullary border produces only isolated $a$ and $\beta$ cortical responses, with features identical with responses to stimulation of an isolated strand of the medullary pyramid. In the present experiments, stimulation rostrally to pyramidal transection produced only $a$ and $\beta$ responses when the intensities were carefully 
adjusted to be well below the threshold of the delayed $b$ or $d$ responses. As expected, strong pyramidal stimulation caudally to the transection produced the late orthodromic responses, with a very faint $a$ potential probably via cortico-bulbar fibers deep to the pyramidal tract ${ }^{23)}$.

Because the pyramidal tract was transected between the former (rostral) stimulating electrodes and the pyramidal collaterals to the dorsal column nuclei ${ }^{18,26,32)}$, it seems unlikely that the VB neuron responses were mediated by that way. Moreover, the latencies of VB neuronal response to pyramidal stimulation (FIG. 9F, the shortest latency of $1.2 \mathrm{msec}$.) were not significantly longer than the latencies to cortical stimulation (FIG. $4 \mathrm{C}$, the shortest of 1.3 msec.) and those to medial lemniscal stimulation (the shortest of $1.4 \mathrm{msec}$.). This suggests that the VB neuronal response is not a secondary result of cortical or bulbar excitation produced by pyramidal impulses. Further, ascending fibers in the pyramidal tract, such as described by BRODAL and WALBERG $^{\text {7) }}$, do not seem to be involved, because after pyramidal degeneration resulting from chronic cortical ablation, no VB neurons responded to pyramidal stimulation at intensities just below the threshold of the $b$ lemniscal response. This is additional support for the presumption that the pyramidal evocation of VB units in the intact cat does not depend on current spread to lemniscal fibers. It seems likely, therefore, that stimulation of the pyramid under these conditions gives rise to antidromic impulses in pyramidal tract fibers, which pass to the VB complex via collaterals and excite the VB neurons, in some cases probably monosynaptically. The same considerations suggest strongly that trans-synaptic excitation of VB neurons by cortical stimulation may occur orthodromically along these same fibers.

Fewer VB units were excited by pyramidal stimulation than by cortical stimulation under the conditions of the present experiments. This probably due to the low intensities of pyramidal stimulation used.

As regards the cortical potentials evoked by strong stimulation of the pyramid, the late orthodromic responses may not be exclusively due to spread of stimulating current to the medial lemniscus, but partly ascribable to excitation of VB neurons by conduction along these pyramidal collaterals.

The latencies of the earliest spikes evoked in VB neurons by medial lemniscal stimulation were $1.4-2.0 \mathrm{msec}$. This contrasts with the fastest (antidromically measured) conduction time between the same two points, which averaged $0.85 \mathrm{msec}$. Thus it appears likely that some of the early evoked spikes were excited monosynaptically by lemniscal stimulation (cf. FIG. 6Aa). Since, however, the same stimulation also frequently gave rise to repetitive responses of longer latency (cf. FIG.7Aa), polysynaptic mechanisms also were probably involved. Current spread to neighboring structures, such as the brain stem reticular formation or the presynaptic fibers of the dorsal column nuclei might also be involved. Hence it is possible that cortical inhibitory 
effects on the reticular formation ${ }^{1)}$ and on the dorsal column nuclei ${ }^{31}$ play some role in the cortical inhibition of thalamic neurons in the intact preparation. After degeneration of corticofugal fibers, however, cortical inhibition of these long latency repetitive spikes was still observed (FIG. 10C), and this did not differ significantly from the effect with intact cortex (FIG. 7B). Moreover, the inhibitory fields in the chronically decorticated and intact animals were similar in extent. These observations suggest that the inhibition of VB neurons from the intact postcruciate cortex depends on antidromic influences via thalamo-cortical fibers. The slight inhibition seen after pyramidal conditioning stimulus may also be attributed to the secondary effect of firing of some VB neurons. If cortico-reticular or cortico-thalamic fibers do not degenerate at about the same rate as cortico-pyramidal fibers, these suggestions should probably be reconsidered, because in the present experiments, only the cortico-pyramidal system was checked for loss of ability to conduct impulses following chronic cortical ablation.

The present experiments demonstrate that the area of postcruciate cortex from which corticofugal excitation of a VB neuron is obtained (an area which includes the locus for antidromic activation) is surrounded by a more extensive cortical field where stimulation produces antidromic inhibition of the same neuron. Since the thalamic terminations of sensory systems and thalamocortical projections show the same topographical organization ${ }^{27)}$, these results suggest that excitation of a restricted area in the somatosensory cortex produces excitation of the corresponding VB neurons through axon collaterals of the pyramidal tract fibers, with secondary inhibition of surrounding VB neurons. This inhibition may possibly be caused by recurrent activity described by ANDERSON and ECCLES ${ }^{2)}$. These cortical influences undoubtedly function to sharpen incoming general sensory impulses, as has been reported with various kinds of sensory systems $\mathrm{s}^{10,13,20,28,34)}$.

An important observation of IWAMA ${ }^{15)}$ has been confirmed in the present experiments, namely, that the number of spikes evoked in the VB neuron by lemniscal stimulation increases during an immediate post-conditioning period. This increase was usually observed $100-200 \mathrm{msec}$. after cortical conditioning, during which time the latencies always remained prolonged (cf. FIG. 7B and FIG. 10C).

To account for this observation, the following mechanisms may be proposed. Firstly, since it seems probable that the later spikes in response to test stimulation are cut off by inhibitory influences from surrounding VB neurons, the state of excitation of these surrounding neurons is of great importance. When the surrounding neurons are inhibited by cortical conditioning, the original VB neuron will be subject to less inhibitory infiuence from the surrounding neurons. Hence the cut-off effect on the later spikes will decrease, with resultant increase of evoked unit responses. The prolongation 
of latency is probably a manifestation of inhibition caused by cortical conditioning.

A second possible mechanism of this delayed hyperactivity is that the test shock may arrive at the VB neuron during hyperpolarization due to the cortical stimulation ${ }^{2}$, and the number of evoked spikes then will be increased because of post-anodal exaltation.

IWAMA and YAMAMOTO ${ }^{16)}$ and $\mathrm{OGDEN}^{29)}$ suggested that corticofugal inhibitory influences on VB neurons may be present, but under the present experimental conditions such corticofugal inhibitory effects were difficult to distinguish from the strong antidromic inhibitory influences which are clearly present. Further investigation will be necessary to clarify this.

\section{SUMMARY}

1. The effects of electrical stimulation of the pericruciate cortex on individual neurons of the ventrobasal complex (VB) of the thalamus has been studied in cats. Extracellular recording was via glass micropipettes. Unit spikes were evoked by single test shocks applied either to peripheral nerves or to the medial lemniscus.

2. About half the neurons tested were excited antidromically by single shocks to restricted areas of the postcruciate cortex. Similar stimulation caused trans-synaptic excitation in about one third of the neurons.

3. When these and adjacent areas of postcruciate cortex were weakly stimulated prior to the medial lemniscal test shock, the VB unit was commonly inhibited. The inhibitory effect usually lasted $300 \mathrm{msec}$. or more.

4. Some VB neurons were excited by stimulation of the ipsilateral pyramid at the ponto-bulbar border. The specificity of this pyramidal stimulation was checked by monitoring antidromically evoked cortical potentials.

5. Twenty-two to 30 days following cortical ablation, with degeneration of the descending pyramidal fibers, stimulation of the exposed subcortical white matter had an antidromic inhibitory effect on the VB neurons. No transsynaptic excitation was produced in these cases either by stimulation of subcortical white matter or the medullary pyramid.

6. These results suggest that some axon collaterals of pyramidal tract fibers project to the VB complex and produce excitation of small groups of VB neurons, which in turn results in inhibition of surrounding VB neurons. Possible functional significance of the results was briefly discussed.

The authors wish to express their thanks to Prof. T. Tokizane and to Prof. T. Kusama for their valuable advice and encouragement, and to Miss T. SAto for histological preparations. 


\section{REFERENCES}

1) Adey, W.R., Segundo, J.P., And Livingston, R. B. Corticofugal influences on intrinsic brainstem conduction in cat and monkey. J. Neurophysiol., 20:1-16, 1957.

2) Andersen, P. And Eccles, J. Inhibitory phasing of neuronal discharge. Nature, $196:$ : 645-647, 1962.

3) Andersen, P., Eccles, J.C. And Sears, T.A. Cortically evoked depolarization of primary afferent fibers in the spinal cord. J. Neurophysiol., 27 : 63-77, 1964.

4) Auer, J. Terminal degeneration in the diencephalon after ablation of frontal cortex in the cat. J. Anat., 90:30-41, 1956.

5) Bishop, P.O., Burke, W. And Davis, R. The identification of single units in central visual pathways. J. Physiol., 162: 409-431, 1962.

6) Brock, L. G., Coombs, J.S., And Eccles, J.C. Intracellular recording from antidromically activated motoneurons. J. Physiol., 122: 429-461, 1953.

7) Brodal, A. And Walberg, F. Ascending fibers in pyramidal tract in cat. Arch. Neurol. Psychiat., Chicago, 68: 7j5-775, 1952.

8) Burns, B. O. The Mammalian Cerebral Cortex. London, Edward Arnold, 119 pp. 1958.

9) Fuortes, M.G.F., Frank, K. And Becker, M.C. Steps in the production of motoneuron spikes. J. gen. Physiol., 40 : 735-752, 1957.

10) Gordon, G. And Paine, C. H. Functional organization in nucleus gracilis of the cat. J. Physiol., 153: 331-349, 1960.

11) Hagbarth, K. E. And Fex, J. Centrifugal influences on single unit activity in spinal sensory paths. J. Neurophysiol., 22 : 321-338, 1959.

12) Hagbarth, K. E. And Kerr, D. I. B. Central influences on spinal afferent conduction. J. Neurophysiol., $17: 295-307,1954$.

13) Hartline, H. K. And RatlifF, F. Inhibitory interaction of receptor units in the eye of Limulus. J. gen. Physiol., 40: 357-376, 1957.

14) Hernandez-Peon, R. And Hagbarth, K. E. Interactión between afferent and cortically induced reticular responses. J. Neurophysiol., 18: 44-55, 1955.

15) Iwama, K. Central nervous control of sensory perception (in Japanese) Medicine (Sogo-Igaku), 19: 530-535, 1962.

16) Iw Ama, K. And Yamamoto, C. Impulse transmission of thalamic somatosensory relay nuclei as modified by electrical stimulation of the cerebral cortex. Jap. J. Physiol., 11 : 169-182, 1961.

17) Jabbur, S. J. And Towe, A. L. Analysis of the antidromic cortical response following stimulation at the medullary pyramids. J. Physiol., 155: 148-160, 1961.

18) Jabbur, S. J. And Towe, A.L. Cortical excitation of neurons in dorsal column nuclei of cat, including an analysis of pathways. J. Neurophysiol., 24 : 499-509, 1961.

19) Jasper, H. H. And Ajmone-Marsan, C. A stereotaxic Atlas of the Diencephalon of the Cat. Ottawa, National Research Council of Canada, 1954.

20) Katsuki, Y., Watanabe, T. and Maruyama, N. Activity of auditory neurons in upper levels of brain of cat. J. Neurophysiol., 22: 343-359, 1959.

21) Kawana, E. Projections from the sensory motor cortex to the sensory nuclei in cats (in Japanese). Recent Advances in Research of the Nervous System, 7: 464484, 1963.

22) Kennedy, T. T. And Towe, A. L. Identification of a fast lemnisco-cortical system in the cat. J. Physiol., 160:535-547, 1962.

23) Kuypers, H. G. J.M. An anatomical analysis of corticobulbar connexions to the 
pons and lower brain stem in the cat. J. Anat., 92: 198-218, 1958.

24) Lance, J.W. And Manning, R. L. Origin of the pyramidal tract in the cat. $J$. Physiol., 124 : 385-399, 1954.

25) LANDAu, W.M. An analysis of the cortical response to antidromic pyramidal tract stimulation in the cat. EEG clin. Neurophysiol., 8: 445-456, 1956.

26) Levitit, M., Carreras, M., Liu, C. N. and Chambers, W. W. Pathways mediating corticofugal influences on the posterior column nuclei. Anat. Record, 136: 233, 1960.

27) Mountcastle, V.B. And Henneman, E. Pattern of tactile representation in thalamus of cat. J. Neurophysiol., 12: 85-100, 1949.

28) Mountcastle, V.B. and Powell, T.P.S. Neural mechanisms subserving cutaneous sensibility, with special reference to the role of afferent inhibition in sensory perception and discrimination. Bull. Johns Hopkins Hosp., 105: 201-232, 1959.

29) Ogden, T.E. Cortical control of thalamic somato-sensory relay nuclei. EEG clin. Neurophysiol., 12 : 621-634, 1960.

30) Poggio, G.F. And Mountcastle, V.B. A study of the functional contributions of the lemniscal and spinothalamic systems to somatic sensibility. Central nervous mechanisms in pain. Bull. Johns Hopkins Hosp., 106: 266-316, 1960.

31) Towe, A.L. And JabBur, S. J. Cortical inhibition of neurons in dorsal column nuclei of cat. J. Neurophysiol., 24: 488-498, 1961.

32) WAlberg, F. Corticofugal fibres to the nuclei of the dorsal columns. An experimental study in the cat. Brain, 80:273-287, 1957.

33) Woolsey, C. N. And Chang, H.-T. Activation of the cerebral cortex by antidromic volleys in the pyramidal tract. Res. Publ. Ass. nerv. ment. Dis., 27 : 146161, 1948.

34) Yamamoto, C., Yamamoto, T. and Iwama, K. The inhibitory systems in the olfactory bulb studied by intracellular recording. J. Neurophysiol., 26: 403-415, 1963. 